\title{
Endoscopic ultrasound-guided antegrade stenting through a hilar cholangio- carcinoma associated with a severe biliary infection
}

The efficacy of endoscopic ultrasoundguided (EUS) antegrade stenting has been previously reported $[1,2]$. We describe a rare and fatal complication of EUS antegrade stenting.

A 79-year-old woman who had undergone Roux-en-Y reconstruction following total gastrectomy was admitted with jaundice and cholangitis. Computed tomography (CT) showed a large hilar cholangiocarcinoma containing air ( $\mathbf{F i g . 1 )}$ ). Right and left biliary ducts were displaced. Transpapillary biliary drainage using a single-balloon enteroscope failed because the ampulla was not visible owing to tumor invasion. Therefore, we conducted endoscopic ultrasound-guided antegrade stenting ( $\triangleright$ Video 1 ). The B3 branch was punctured. Although we intended to advance a guidewire into the duodenum through the common bile duct, the guidewire was advanced into the duodenum through the tumor. The first stent (Zilver 635, 10-mm, 6-Fr; Cook Medical, Bloomington, Indiana, USA) was deployed over the guidewire. Subsequently, an additional guidewire was inserted into the right hepatic duct, and the second stent (Zilver 635, 10-mm, 6-Fr) was deployed in a side-byside configuration. Finally, a plastic stent (TYPE-IT stent; Gadelius Medical Co. Ltd., Tokyo, Japan) was also deployed from the initial stent to the jejunum ( $\mathbf{F i g . 2}$ ). Although the postoperative CT revealed that the initial stent was deployed through the tumor ( $\triangleright$ Fig.3), early adverse events were not observed. The symptoms were resolved. However, she presented with a severe biliary infection 1 month later. CT revealed a large amount of air in the tumor and biliary tract ( $\triangleright$ Fig. 4 ). She died 24 hours after developing sepsis. The autopsy revealed a large fistula between the tumor and duodenum. We considered that the initial stent through the tumor was associated with the biliary infection because the stent was inside the fistula.

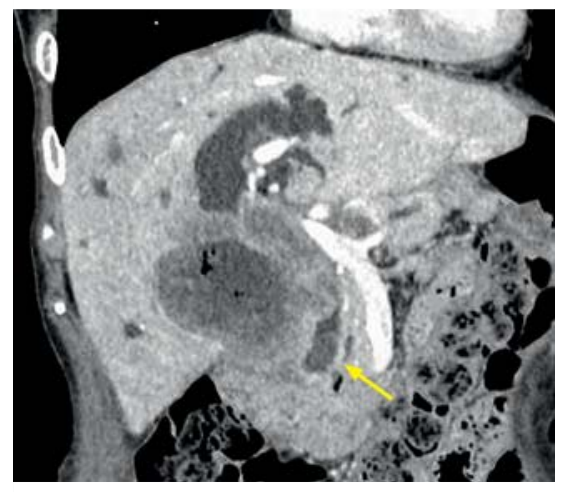

- Fig. 1 Computed tomography showing a large hilar cholangiocarcinoma containing air. The common bile duct is indicated by the arrow.

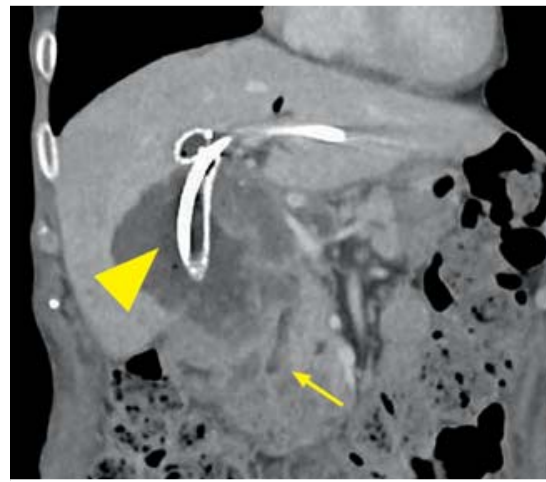

Fig. 3 Computed tomography showing a biliary stent deployed through the tumor (arrowhead). The common bile duct is indicated by the arrow.

Endoscopists need to recognize that a guidewire may be easily advanced into a tumor. When such situations are noticed, conducting a simple EUS-guided hepaticojejunostomy should be considered.

Endoscopy_UCTN_Code_CPL_1AK_2AI

\section{Competing interests}

The authors declare they have no conflict of interest

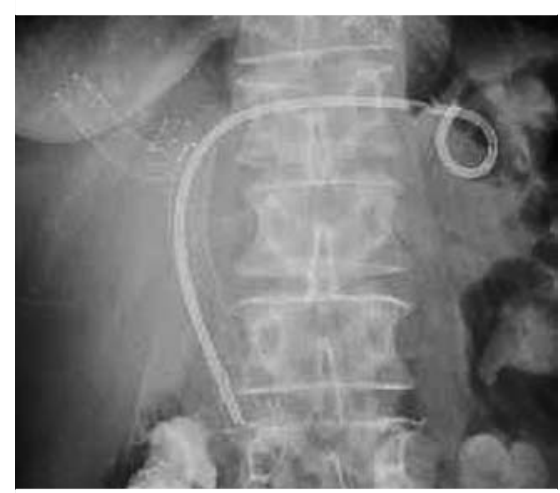

- Fig. 2 X-ray image after endoscopic ultrasound-guided antegrade stenting.

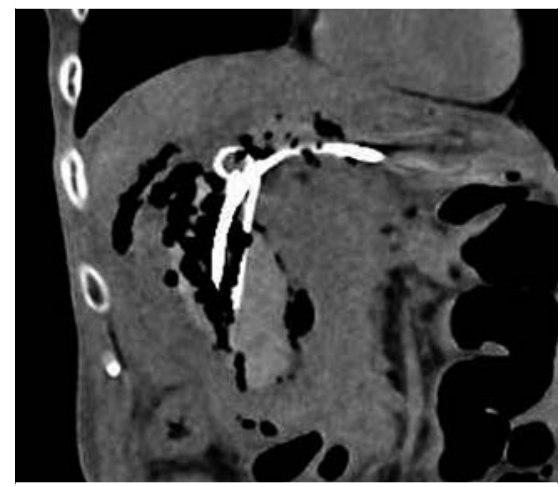

- Fig. 4 Computed tomography showing a large amount of air in the tumor and biliary tract.

The authors

Hirofumi Harima, Seiji Kaino, Yuko Fujimoto, Shogo Amano, Isao Sakaida

Department of Gastroenterology and Hepatology, Yamaguchi University Graduate School of Medicine, 1-1-1 Minami-Kogushi, Ube, Yamaguchi 755-8505, Japan 


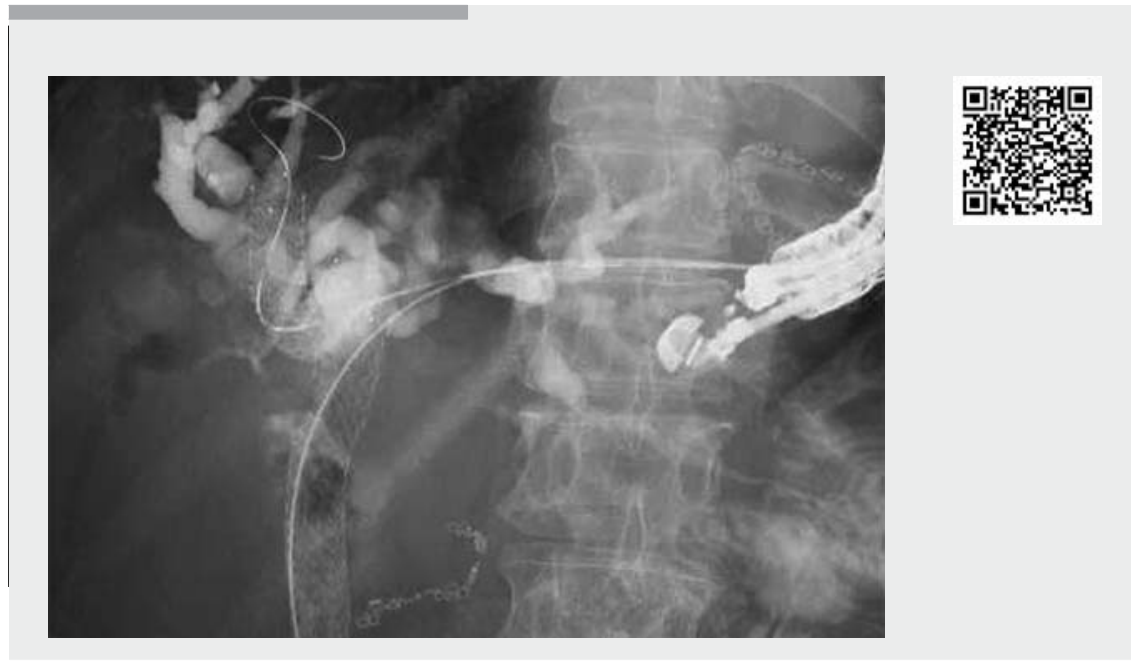

$\checkmark$ Video 1 Complication of endoscopic ultrasound-guided antegrade stenting. A guidewire was advanced into the duodenum through the tumor, and a metal stent was deployed over the guidewire.
Bibliography

DOI https://doi.org/10.1055/a-1122-8379

Published online: 18.3 .2020

Endoscopy 2020; 52: E342-E343

(c) Georg Thieme Verlag KG

Stuttgart · New York

ISSN 0013-726X

\section{ENDOSCOPY E-VIDEOS}

https://eref.thieme.de/e-videos

回回 Endoscopy E-Videos is a free

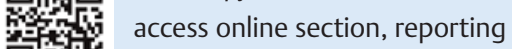
靣轱: on interesting cases and new techniques in gastroenterological endoscopy. All papers include a high quality video and all contributions are freely accessible online.

This section has its own submission website at https://mc.manuscriptcentral.com/e-videos

\section{Hirofumi Harima, MD}

Department of Gastroenterology and Hepatology, Yamaguchi University Graduate School of Medicine, 1-1-1 Minami-Kogushi, Ube, Yamaguchi 755-8505, Japan Fax: +81-836-519391

harima@yamaguchi-u.ac.jp

\section{References}

[1] Yamamoto K, Itoi T, Tsuchiya T et al. EUSguided antegrade metal stenting with hepaticoenterostomy using a dedicated plastic stent with a review of the literature (with video). Endosc Ultrasound 2018; 7: 404-412

[2] Iwashita T, Yasuda I, Mukai T et al. Endoscopic ultrasound-guided antegrade biliary stenting for unresectable malignant biliary obstruction in patients with surgically altered anatomy: Single-center prospective pilot study. Dig Endosc 2017; 29: 362-368 